\title{
Trends of incidence and treatment strategies for operatively treated distal fibula fractures from 2005 to 2019: a nationwide register analysis
}

\author{
Alexander Milstrey ${ }^{1}$ (D) Sebastian Felix Baumbach ${ }^{2} \cdot$ Alexander Pfleiderer $^{1} \cdot$ Julia Evers $^{1} \cdot$ Wolfgang Boecker $^{2}$. \\ Michael J Raschke ${ }^{1} \cdot$ Hans Polzer $^{2} \cdot$ Sabine Ochman ${ }^{1}$
}

Received: 14 August 2021 / Accepted: 18 October 2021 / Published online: 7 November 2021

(c) The Author(s) 2021

\begin{abstract}
Introduction Valid epidemiological data about distal fibular fractures and their treatment strategies are missing. Innovative osteosynthesis techniques were introduced and improved during the past 15 years. The aim of this study was to investigate the epidemiologic development and the implementation of new treatment strategies in a nationwide register in Germany over a period of 15 years.

Materials and methods Data of the German Federal Statistical Office from 2005 until 2019 were screened. Adults with a fracture of the distal fibula were included. Data were separated for gender, age and treatment strategy.

Results During the past 15 years, there was a steady annual incidence of distal fibula fractures of $74 \pm 32$ per 100,000 people without any significant changes $(p=0.436) .60 .1 \% \pm 0.6 \%$ of all fractures occurred in females. The annual incidence for male was nearly constant over the different age groups, whereas for female, there was a clear increase in incidence above the age of 40 . Whereas $66 \%$ of fractures in between 20 and 30 years of age occurred in male, approximately $70 \%$ of fractures above the age of 60 occurred in females. The relative quantity of locking plates increased from 2\% in 2005 to $34 \%$ in 2019. In 2019 , only $1.02 \%$ of the patients were operated with an intramedullary nail.

Conclusions Operatively treated distal fibular fractures revealed an age dependent increase in incidence in postmenopausal women compared to younger females. Regarding the treatment strategy, there was an increase in application of locking plates. The data implicate a typical fragility fracture related age and gender distribution for distal fibula fractures.
\end{abstract}

Keywords Ankle fracture $\cdot$ Distal fibula fracture $\cdot$ Epidemiology $\cdot$ Treatment strategy $\cdot$ Locking plate $\cdot$ Fibula nail

\section{Introduction}

Ankle fractures are among the most common fractures in adult people [1]. There is a major research focus on gaining inside into the individual and general factors associated to this injury. This is the prerequisite to enhance the treatment quality, leading to a better outcome and a reduction of the socioeconomic burden. National registries enable

Alexander Milstrey

Alexander.Milstrey@ukmuenster.de

1 Department of Trauma-, Hand- and Reconstructive Surgery, University Hospital Muenster, WWU Muenster, Waldeyer Street 1, 48149 Muenster, Germany

2 Department of Orthopaedics and Trauma Surgery, Musculosceletal University Center Munich (MUM), University Hospital, LMU Munich, Munich, Germany researchers not only to analyze the incidence of ankle fractures, but also to monitor the implementation of novel treatment strategies in daily practice.

Reported incidence rates range from 42 to $187 / 100,000$ people per year [2-7], increasing to $300 / 100,000$ people per year in the elderly population. [8-10] But, the majority of these studies are based on data of single centers and are, therefore, limited by a selection bias and by sample size. Data from national registries overcome both of these limitations [11]. To our best knowledge, Thur et al. [5] published the only long-term national register study on ankle fractures. The reported annual ankle fracture incidence in Sweden was $71 / 100,000$ people per year without significant alterations over the observed study period. However, the data presented covered a rather historic period from 1987 to 2004. Therefore, we are missing current and valid data on the incidence of ankle fractures. 
Thur et al. [5] did also not report on the frequencies of different treatment strategies and their development over time. In the last two decades, several new exciting treatment strategies have been developed. These include anatomical locking plates [12] and intramedullary nails[13] for distal fibular fractures. Locking plates and intramedullary nails were designed predominantly for the elderly population, as they were shown to enhance the biomechanical stability and reduce wound healing problems especially in patients at risk [14-19]. However, the authors are not aware of any study evaluating the actual implementation of these modern treatment strategies into daily practice.

The aim of the present study was, therefore, to evaluate the incidence and treatment strategies for operatively treated ankle fractures with a fracture to the lateral malleolus in the most populous country in Europe over a 15-year period based on national registry data.

\section{Materials and methods}

The herein presented study is a longitudinal national registry study based on anonymized data sets. Therefore, the study needed no approval of the local ethics committee.

\section{National registry}

In Germany, any in-house medical procedure must be reported to the German Federal Statistical Office to receive payment for the reported case [20]. Therefore, every German hospital contributes to the national registry and every in-house procedure is recorded. Data are transmitted anonymized and coded based on the German procedure classification system (OPS). The annual data sets can be purchased publicly through the German Federal Statistical Office and form the basis for the official annual national health care report. Each annual data set provides the OPS codes separated by age in 5-year increments and gender (male, female). For the current study, the data sets of the past 15 years (2005-2019) were purchased, comprising of a total amount of $266,911,590$ procedures.

\section{Data analysis}

The aim was to identify all procedures related to distal fibula fractures in adult patients ( $\geq 20$ years). Therefore, the data set was screened for the following OPS codes: 5-790.3r, 5-790.4r, 5-790.4r, 5-793.3r, 5-793.ar, 5-793.br, 5-793.cr, 5-793.kr, 5-794.2,, 5-794.ar, 5-794.br, 5-794.cr, 5-794.gr, 5-794.kr (Supp. 1).

The resulting 15 individual data sets were merged, and the age groups recalculated to 10-year increments (20-29 years, 30-39 years, 40-49 years, etc.). The annual incidence was calculated as the sum of all procedures per year (sum out of all OPS codes) divided by the year- and age-matched German population. Annual population data were also retrieved from the German Federal Statistical Office [21]

The second aim of this study was to evaluate the treatment trends over the past two decades for anatomical locking plates and intramedullary nails. Therefore, the OPS codes and incidences were grouped according to these treatment strategies: Conventional plates (OPS codes: 5-793.3r, 5-794.2), angular stable plates (OPS codes: 5-793.kr, 5-794.kr), fibular nails (OPS codes: 5-790.3r, 5-790.4r, 5-790.5r, 5-793.ar, 5-793.br, 5-793.cr, 5-794.ar, 5-794. br, 5-794.cr). Based on these data sets, the treatment trends over the 15-year period as well as a possible influence of age or gender was investigated.

\section{Statistics}

Next to descriptive statistics, a linear regression analysis was performed to analyze the incidence and age distribution. A Chi-squared-test was conducted for analysis of treatment strategies. Values are presented as mean \pm standard deviation if not stated differently. All statistics were performed with SPSS Statistics (V27.0, IBM, Armonk, NY, USA). In all cases, significance was set at $p<0.05$.

\section{Results}

Between 2005 and 2019 a total of 745,823 ankle fractures with an involvement of the lateral malleolus were treated surgically in Germany. On average, 49,721 $\pm 5,464$ (range $41,925-66,254)$ fractures were treated surgically per year (Fig. 1A). The patients' mean age was 56.1 years (female: 60.5 years; male: 50.4 years) and $60.1 \% \pm 0.6 \%$ (range $59.2-61.0 \%)$ of fractures occurred in females. The mean incidence per 100,000 inhabitants per year was $74 \pm 32$ (range 63.3-99.6) with no significant differences between 2005 and $2019(p=0.436)$.

Figure 1B illustrates the mean incidence per 100,000 inhabitants per year according to the different age groups. The overall mean incidence revealed a peek between 60 and 80 years. Whereas the incidence for male patients showed no considerable age difference, the incidence for female patients did show a significant major increase between 40 and 70 years $\left(R^{2}=0.943, p=0.006\right)$. This age-gender dependency is further highlighted in Fig. 1C. Whereas 66\% of ankle fractures in patients aged 20-30 years occurred in males, approximately $70 \%$ of fractures in patients aged more than 60 years occurred in females.

Figure 2 illustrates the treatment trends for non-locking conventional vs. locking plates. For the observed 15 -year time period, the proportion of locking plates, compared 

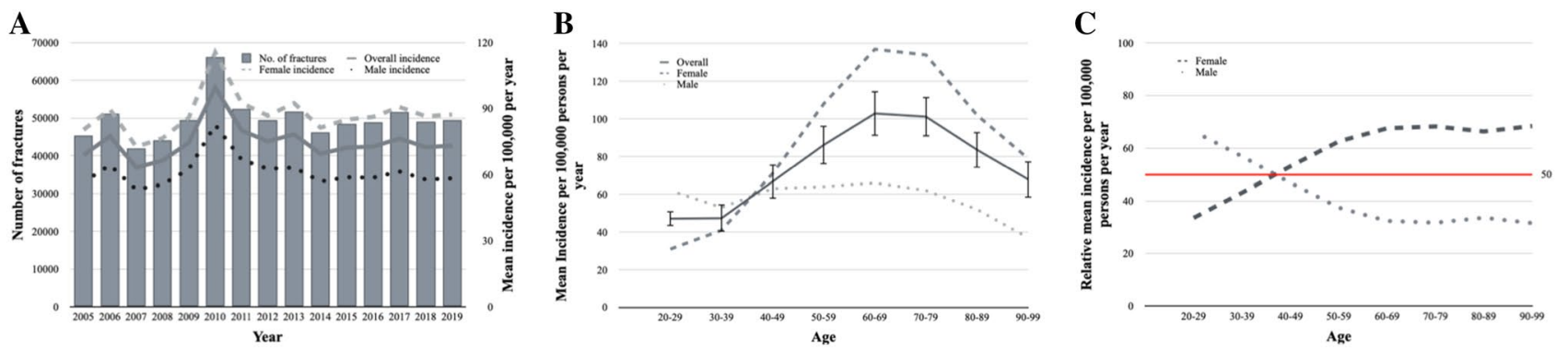

Fig. 1 A Annual incidence. Bars: Absolute number of distal fibula fractures per year from 2005 to 2019 , scale left side; lines: mean incidence per year per 100,000 persons separated for gender, scale on the right side. B Age distribution. Average mean incidence of distal fib-

ula fractures per 100,000 persons per year separated for gender from 2005 to 2019. C Gender gap. Average relative mean incidence per 100,000 persons per year from 2005 to 2019

A

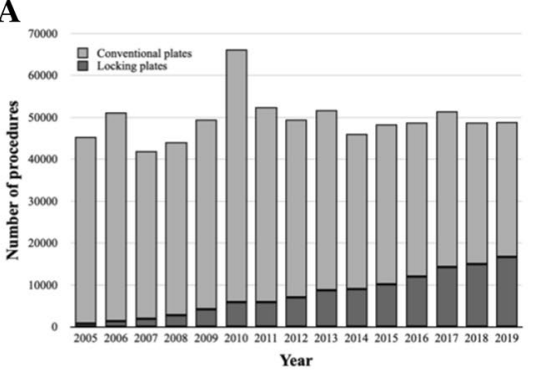

B

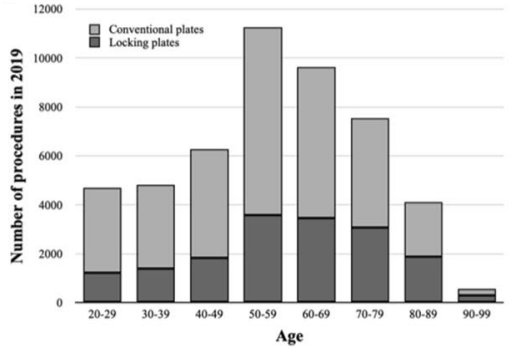

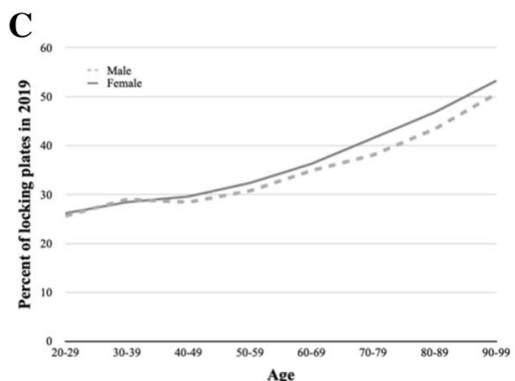

Fig. 2 Locking plates vs. conventional plates. A Annual trends of utilized plate osteosynthesis from 2005 to 2019. B Age-dependent distribution in 2019. C Gender distribution in age-dependent ratio of angular stable locking plates in 2019
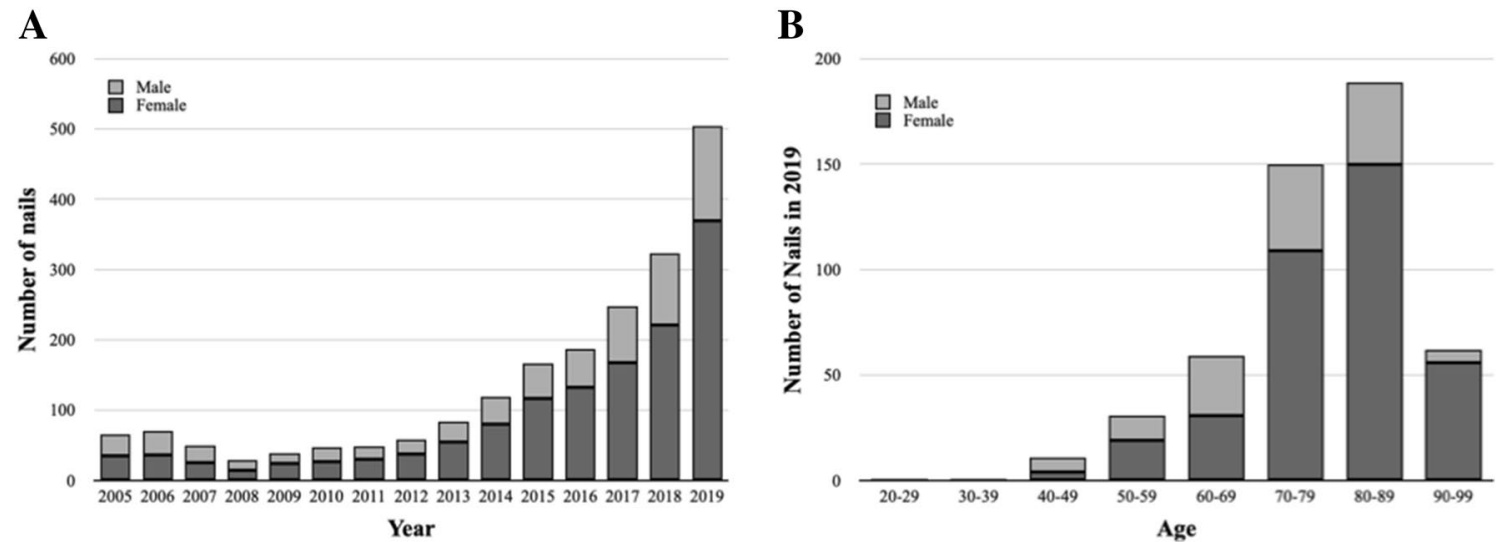

Fig. 3 Intramedullary nails for distal fibula fractures. A Absolute annual number per year from 2005 to 2019, separated for gender. B Agedependent distribution in 2019

to conventional plates, increased significantly from $2 \%$ in 2005 to $34 \%$ in 2019 ( $p<0.0001$; Fig. 2A). For 2019, the patients' age showed a high correlation to the relative frequency of locking plates $\left(R^{2}=0.937, p<0.001\right.$; Fig. 2B $)$. Interestingly, no relevant gender difference could be observed for the application of locking plates $(p=0.712$; Fig. 2C).
Figure 3 illustrates the treatment trends for intramedullary fibular nails. The proportion of fibular nails overall increased significantly from $0.1 \%$ in 2005 to $1.0 \%$ in $2019\left(R^{2}=0.658, p<0.001\right.$; Fig. 3A). Based on the 2019 data, there was a significant positive correlation between patients' age and the relative frequency of intramedullary nails $\left(R^{2}=0.664, p=0.014\right.$, see Fig. $\left.3 \mathrm{~B}\right)$. Contrary to the 
locking plates, intramedullary nails were more often used in female patients, increasing significantly with age to a peak of $89 \%$ female nails in the age group $90-99$ years $\left(R^{2}=0.976\right.$, $p<0.001$; Fig. 3B).

\section{Discussion}

The analysis of national registries do not only allow to calculate precise epidemiological data, but also give an unbiased inside into the treatment reality and trends. The herein analyzed OPS data sets of the German Federal Statistical Office revealed a rather constant incidence for operatively treated ankle fractures involving the lateral malleolus over the past 15 years. Incidence rates varied considerably per age and sex. Whereas $66 \%$ of all fractures occurred in male patients in the age group 20-30 years, approximately $70 \%$ of all fractures occurred in female patients in the age group 60 years and above. Over the observed time period the proportion of locking plates for the distal fibula increased 17 -fold and for fibular nails tenfold.

As outlined in the introduction, published incidence rates range considerably from 42 to $187 / 100,000$ people per year $[2-7,22]$. In contrast to the previous studies, we were only able to analyze the incidence of operatively treated ankle fractures with a fracture to the lateral malleolus. However, the threshold in Germany is very low for a surgical treatment decision, especially in younger patients [23]. The herein reported mean incidence rate of $74 \pm 32$ (range 63.3-99.6) surgically treated fractures per 100,000 inhabitants is, therefore, in the range of previously published studies. Interestingly, we found no significant difference in the incidence of operatively treated ankle fractures for the observed 15 -year period. Kannus et al. described a massive increase of the incidence of ankle fractures in elderly patients from $57 / 100,000$ people per year in 1970 to $150 / 100,000$ people per year in 2000 [24]. However, the same authors showed in a follow-up study a steady incidence of 144/100,000 inhabitants per year between 1997 and 2004 [9]. A regional registry study by Elsoe et al. [4] demonstrated a constant incidence of ankle fractures in Denmark for a 10-year period between 2005 and 2014 with an incidence of 168.7/100,000 inhabitants per year [4].

Similar to previous studies, the herein presented study revealed an effect of gender and age to the incidence rates. Scheer et al. [2] analyzed the US National Electronic Injury Surveillance System from 2012 to 2016, which records any patients presenting to a US hospital emergency department. They reported an incidence of 42.2/100,000 people with an overall female dominance of $56 \%$ [2]. In line with our results, they described an age-dependent shift of the gender distribution with a male dominance $<30$ years and an increasing relative female incidence of up to $70 \%$ for people older than 80 years [2]. Juto et al. [3] analyzed data from any hospital in Norrbotten County in Sweden from 2009 to 2013 and found an annual incidence of 179/100,000 persons, again with a higher percentage of female patients (58.4\%) [3]. Again, the fracture incidence for female patients increased at the age of 30 , whereas that of male patients showed a homogeneous distribution across all age groups. Tarantino et al. [8] conducted a 3-year study analyzing the hospitalization rate for various fractures, including ankle fractures, in people 45 years or above at 10 major Italian emergency departments. They reported a three times higher hospitalization rate for female patients above an age of 65 years [8]. In a prospective study of almost 8.000 people above the age of 55 years, Schuit et al. observed an almost four times higher incidence for female ankle fracture than for mens' [25]. Consequently, the literature points, in line with our data, to a strong age-gender dependency of ankle fractures. The high percentage of male patients in the below 30 -year groups could well be explained by risk behavior. The high female incidence for age groups above 40 years might indicate an association of ankle fractures to age and gender dependent bone quality impairment. Up to now, ankle fractures are neither considered fragility fractures nor commonly related to osteoporosis as no study has been able to proof a correlation between ankle fractures and a reduced bone mineral density [10, 26-28]. However, previous studies reported microarchitectural alterations on CT scans [29] and a risk increase for subsequent osteoporotic fractures for postmenopausal women with an ankle fracture compared to women without a fracture history [30-32].

This age-related impaired bone quality [10, 27, 28, 33] alongside an age dependent risk for complications [34] led to the development of novel treatment strategies, such as angular stable plates and fibular nails. Interestingly, specific prevalence studies on trends in treatment strategies for distal fibula fractures are spare. Today, it would be inconceivable not to treat a distal radius fracture or proximal humerus fracture with an angular stable implant. Therefore, it appears astonishing, that angular stable plates have not similarly become the standard of care for distal fibular fractures. Even more so, when considering that patients above the age of 75 years are unable to conduct partial weight-bearing [35]. Various authors have reported an increased use of locking plates at individual centers $[36,37]$, but comprehensive registry data are missing. The current study revealed a $+2115 \%$ increase over the observed 15-year time period in a major industrialized country. Controversy, we are still missing convincing evidence, that locking plates do decrease the complication risks compared to conventional plating $[14,38]$ and, therefore, outweigh the higher economic costs of locking plates compared to conventional plates [38].

Intramedullary nails for distal fibular fractures bear the advantage of reducing the invasiveness of the procedure at 
the cost of the quality of reduction. However, previous studies demonstrated not only fewer complications of intramedullary nails compared to standard plate osteosynthesis, but also an equal functional outcome [39, 40]. Despite an increase in the prevalence especially since 2012 , the present study revealed a striking low quantity of 504 (1.01\% of all osteosynthesis procedures) intramedullary nails used in distal fibula fractures in 2019. Scott et al. demonstrated a prevalence of intramedullary fixation for ankle fractures up to $20 \%$ in a recent british long-term register analysis [22]

There are certainly limitations to this study. The OPS data are a nationwide comprehensive data set, but as they provide data only on operatively treated patients, one cannot conclude the true incidence of these injuries, but rather the incidence of the performed surgeries. However, in Germany, there is a traditional low threshold for a surgical indication, especially in younger patients [23]. Therefore, the herein presented data rather underestimated the observed age-dependent incidence relation. Furthermore, the general incidence of 74 per 100,000 people per year is in line with a previous study from Thur et al. [5], who showed in a comparable nationwide analysis in Sweden an incidence of 71 ankle fractures per 100,000 inhabitants per year. The OPS codes themselves have limitations. They are directly linked to the case value and are a simplification of the actual fracture pattern. For example, multifragmentary fractures often have a higher case value than simple fractures and the OPS code does not allow to differentiate between medial and posterior malleolus fractures. To control for these OPS-inherent limitations, the authors focused on distal fibular fractures only and cumulated the corresponding OPS-codes. However, previous studies showed that in $75-90 \%$ of ankle fractures a fracture to the distal fibula was present [4, 7, 41, 42]. Finally, as the data are anonymized by the German Federal Statistical Office except for sex and age, one cannot conclude by the OPS code to the actual type of ankle fracture. Therefore, a possible influence of injury severity and the osteosynthesis strategy cannot be drawn. Despite these limitations, the herein analyzed data set is a complete representation of the treatment strategy in the most populous country in Europe.

In conclusion, the herein presented study is the first to present the incidence and treatment strategies for operatively treated distal fibula fractures between 2005 and 2019. Based on national registry data, a constant incidence rate was found with a gender and age dependent distribution. The treatment strategy over the observed 15-year period showed a steep increase for locking plates and intramedullary nails.

Supplementary Information The online version contains supplementary material available at https://doi.org/10.1007/s00402-021-04232-0.

Author contributions $\mathrm{AM}, \mathrm{AP}$ and $\mathrm{SFB}$ aquired the data, $\mathrm{AM}, \mathrm{SFB}$ and JE analyzed the data, AM created the figures, AM wrote the manuscript. SFB designed the study. JE created the figures. WB, MR,
HP and SO concepted the study and interpreted the data. All authors revised and edited the manuscript.

Funding Open Access funding enabled and organized by Projekt DEAL. No funding was received for conducting this study.

\section{Declarations}

Conflict of interest The authors have no relevant financial or non-financial interests to disclose.

Ethical approval The herein presented study is a longitudinal national registry study based on anonymized data sets. Therefore, the study needed no approval of the local ethics committee.

Informed consent An individual informed consent was waived due to the public data source without any specific individual patient related information.

Open Access This article is licensed under a Creative Commons Attribution 4.0 International License, which permits use, sharing, adaptation, distribution and reproduction in any medium or format, as long as you give appropriate credit to the original author(s) and the source, provide a link to the Creative Commons licence, and indicate if changes were made. The images or other third party material in this article are included in the article's Creative Commons licence, unless indicated otherwise in a credit line to the material. If material is not included in the article's Creative Commons licence and your intended use is not permitted by statutory regulation or exceeds the permitted use, you will need to obtain permission directly from the copyright holder. To view a copy of this licence, visit http://creativecommons.org/licenses/by/4.0/.

\section{References}

1. Baron JA, Barrett JA, Karagas MR (1996) The epidemiology of peripheral fractures. Bone 18:S209-S213. https://doi.org/10.1016/ 8756-3282(95)00504-8

2. Scheer RC, Newman JM, Zhou JJ et al (2020) Ankle fracture epidemiology in the united states: patient-related trends and mechanisms of injury. J Foot Ankle Surg 59:479-483. https://doi.org/ 10.1053/j.jfas.2019.09.016

3. Juto H, Nilsson H, Morberg P (2018) Epidemiology of adult ankle fractures: 1756 cases identified in Norrbotten County during 2009-2013 and classified according to AO/OTA. Bmc Musculoskelet Di 19:441. https://doi.org/10.1186/s12891-018-2326-x

4. Elsoe R, Ostgaard SE, Larsen P (2018) Population-based epidemiology of 9767 ankle fractures. Foot Ankle Surg 24:34-39. https:// doi.org/10.1016/j.fas.2016.11.002

5. Thur CK, Edgren G, Jansson K-Å, Wretenberg P (2012) Epidemiology of adult ankle fractures in Sweden between 1987 and 2004. Acta Orthop 83:276-281. https://doi.org/10.3109/17453674.2012. 672091

6. Lacombe J, Cairns BJ, Green J et al (2016) The effects of age, adiposity, and physical activity on the risk of seven site-specific fractures in postmenopausal women. J Bone Miner Res 31:15591568. https://doi.org/10.1002/jbmr.2826

7. Daly PJ, Fitzgerald RH, Melton LJ, Llstrup DM (2009) Epidemiology of ankle fractures in Rochester, Minnesota. Acta Orthop Scand 58:539-544. https://doi.org/10.3109/17453678709146395

8. Tarantino U, Capone A, Planta M et al (2010) The incidence of hip, forearm, humeral, ankle, and vertebral fragility fractures in 
Italy: results from a 3-year multicenter study. Arthritis Res Ther 12:R226. https://doi.org/10.1186/ar3213

9. Kannus P, Palvanen M, Niemi S et al (2008) Stabilizing incidence of low-trauma ankle fractures in elderly people Finnish statistics in 1970-2006 and prediction for the future. Bone 43:340-342. https://doi.org/10.1016/j.bone.2008.04.015

10. Hasselman CT, Vogt MT, Stone KL et al (2003) Foot and ankle fractures in elderly white women: incidence and risk factors. J Bone Jt Surg Am 85:820-824. https://doi.org/10.2106/00004623200305000-00008

11. Milstrey A, Domnick C, Garcia P et al (2020) Trends in arthrodeses and total joint replacements in foot and ankle surgery in Germany during the past decade-back to the fusion? Foot Ankle Surg. https://doi.org/10.1016/j.fas.2020.05.008

12. Fatayri BE, Bulaïd Y, Djebara A-E et al (2019) A comparison of bone union and complication rates between locking and nonlocking plates in distal fibular fracture: retrospective study of 106 cases. INJ 50:2324-2331. https://doi.org/10.1016/j.injury.2019. 10.001

13. Jain S, Haughton BA, Brew C (2014) Intramedullary fixation of distal fibular fractures: a systematic review of clinical and functional outcomes. J Orthop Traumatol 15:245-254. https://doi.org/ 10.1007/s10195-014-0320-0

14. Shih C-A, Jou I-M, Lee P-Y et al (2020) Treating AO/OTA 44B lateral malleolar fracture in patients over 50 years of age: periarticular locking plate versus non-locking plate. J Orthop Surg Res 15:112. https://doi.org/10.1186/s13018-020-01622-9

15. Zahn RK, Frey S, Jakubietz RG et al (2012) A contoured locking plate for distal fibular fractures in osteoporotic bone: a biomechanical cadaver study. INJ 43:718-725. https://doi.org/10.1016/j. injury.2011.07.009

16. Switaj PJ, Fuchs D, Alshouli M et al (2016) A biomechanical comparison study of a modern fibular nail and distal fibular locking plate in AO/OTA 44C2 ankle fractures. J Orthop Surg Res 11:100. https://doi.org/10.1186/s13018-016-0435-5

17. Tracey J, Vovos TJ, Arora D et al (2019) The use of modern intramedullary nailing in distal fibula fracture fixation. Foot Ankle Spec 12:322-329. https://doi.org/10.1177/1938640018803734

18. Ochman S, Raschke MJ (2021) Sprunggelenkfraktur beim älteren Patienten. Unfallchirurg 124:200-211. https://doi.org/10.1007/ s00113-021-00953-4

19. Kamin K, Notov D, Al-Sadi O et al (2020) Versorgung der Sprunggelenkfraktur. Unfallchirurg 123:43-56. https://doi.org/ 10.1007/s00113-019-00753-x

20. DESTATIS (2021) Case related hospital statistics/surgeries and procedures of inhouse patients in German hospitals. https://www. statistischebibliothek.de/mir/receive/DESerie_mods_00000953

21. DESTATIS (2021) Population: Germany, time point, gender, age groups, nationality. https://www-genesis.destatis.de/genes is $/ /$ online? operation $=$ table $\&$ code $=12411-0009 \&$ bypass $=$ true $\&$ levelindex $=1 \&$ levelid $=162124197344$ \#abreadcrumb

22. Scott LJ, Jones T, Whitehouse MR et al (2020) Exploring trends in admissions and treatment for ankle fractures: a longitudinal cohort study of routinely collected hospital data in England. BMC Health Serv Res 20:811. https://doi.org/10.1186/s12913-020-05682-9

23. Ochman S, Raschke MJ (2021) Operative Versorgung von Bimalleolarfrakturen. Oper Orthop Traumatol 33:91-103. https:// doi.org/10.1007/s00064-021-00704-Z

24. Kannus P, Palvanen M, Niemi S et al (2002) Increasing number and incidence of low-trauma ankle fractures in elderly people: finnish statistics during 1970-2000 and projections for the future. Bone 31:430-433. https://doi.org/10.1016/s8756-3282(02) 00832-3

25. Schuit SCE, van der Klift M, Weel AEAM et al (2004) Fracture incidence and association with bone mineral density in elderly men and women: the Rotterdam Study. Bone 34:195-202. https:// doi.org/10.1016/j.bone.2003.10.001

26. Honkanen R, Tuppurainen M, Kröger H et al (1998) Relationships between risk factors and fractures differ by type of fracture: a population-based study of 12192 perimenopausal women. Osteoporosis Int 8:25-31. https://doi.org/10.1007/s001980050044

27. Morin SN, Lix LM, Leslie WD (2014) The importance of previous fracture site on osteoporosis diagnosis and incident fractures in women. J Bone Miner Res 29:1675-1680. https://doi.org/10. 1002/jbmr.2204

28. Therdyothin A, Phiphopthatsanee N, Wajanavisit W et al (2020) Is ankle fracture related to low bone mineral density and subsequent fracture? A systematic review. Osteoporos Sarcopenia 6:151-159. https://doi.org/10.1016/j.afos.2020.08.003

29. Stein EM, Liu XS, Nickolas TL et al (2011) Abnormal microarchitecture and stiffness in postmenopausal women with ankle fractures. J Clin Endocrinol Metab 96:2041-2048. https://doi.org/ 10.1210/jc.2011-0309

30. Center JR, Bliuc D, Nguyen TV, Eisman JA (2007) Risk of subsequent fracture after low-trauma fracture in men and women. JAMA 297:387-394. https://doi.org/10.1001/jama.297.4.387

31. Lauritzen JB, Lund B (2009) Risk of hip fracture after osteoporosis fractures: 451 women with fracture of lumbar spine, olecranon, knee or ankle. Acta Orthop Scand 64:297-300. https://doi.org/10. 3109/17453679308993629

32. Gehlbach S, Saag KG, Adachi JD et al (2012) Previous fractures at multiple sites increase the risk for subsequent fractures: the global longitudinal study of osteoporosis in women. J Bone Miner Res 27:645-653. https://doi.org/10.1002/jbmr.1476

33. Greenfield DM, Eastell R (2001) Risk factors for ankle fracture. Osteoporosis Int 12:97-103. https://doi.org/10.1007/s001980170 140

34. Shao J, Zhang H, Yin B et al (2018) Risk factors for surgical site infection following operative treatment of ankle fractures: a systematic review and meta-analysis. Int J Surg 56:124-132. https:// doi.org/10.1016/j.ijsu.2018.06.018

35. Kammerlander C, Pfeufer D, Lisitano LA et al (2018) Inability of older adult patients with hip fracture to maintain postoperative weight-bearing restrictions. J Bone Jt Surg 100:936-941. https:// doi.org/10.2106/jbjs.17.01222

36. Huang Z, Liu L, Tu C et al (2014) Comparison of three plate system for lateral malleolar fixation. Bmc Musculoskelet Di 15:360. https://doi.org/10.1186/1471-2474-15-360

37. Schepers T, Lieshout EMMV, Vries MRD, der Elst MV (2011) Increased rates of wound complications with locking plates in distal fibular fractures. Inj 42:1125-1129. https://doi.org/10.1016/j. injury.2011.01.009

38. Moss LK, Kim-Orden MH, Ravinsky R et al (2017) Implant failure rates and cost analysis of contoured locking versus conventional plate fixation of distal fibula fractures. Orthopedics 40:e1024-e1029. https://doi.org/10.3928/01477447-20171012-05

39. White TO, Bugler KE, Appleton P et al (2016) A prospective randomised controlled trial of the fibular nail versus standard open reduction and internal fixation for fixation of ankle fractures in elderly patients. Bone Jt J 98-B:1248-1252. https://doi.org/10. 1302/0301-620x.98b9.35837

40. Asloum Y, Bedin B, Roger T et al (2014) Internal fixation of the fibula in ankle fractures. A prospective, randomized and comparative study: Plating versus nailing. Orthop Traumatol Surg Res 100:S255-S259. https://doi.org/10.1016/j.otsr.2014.03.005

41. Shibuya N, Davis ML, Jupiter DC (2014) Epidemiology of foot and ankle fractures in the United States: an analysis of the National Trauma Data Bank (2007 to 2011). J Foot Ankle Surg 53:606-608. https://doi.org/10.1053/j.jfas.2014.03.011

42. Jensen SL, Andresen BK, Mencke S, Nielsen PT (2009) Epidemiology of ankle fractures: a prospective population-based study 
of 212 cases in Aalborg, Denmark. Acta Orthop Scand 69:48-50. https://doi.org/10.3109/17453679809002356

Publisher's Note Springer Nature remains neutral with regard to jurisdictional claims in published maps and institutional affiliations. 